\title{
Hayer's Legacy and the Future of Liberal Thought: Rational Liberalism VERSUS EVOLUTIONARY AGNOSTICISM Viktor Vanberg
}

F. A. Hayeks' work represents, without doubt, the most comprehensive and influential contribution to what has been described as the modern "rebirth of classical liberalism" (Gray 1982). His legacy will, therefore, surely be of decisive influence on the future development of classical liberal thought.

The issue I address in this paper concerns the implications of Hayek's work for the role of rational institutional design and constructive reform within a liberal political agenda. With regard to this issue Hayek's work appears to contain a fundamental tension between what I call "rational liberalism" and "evolutionary agnosticism." By rational liberalism I mean the message implied in those parts of Hayek's writings that provide rational arguments in favor of the liberal order, arguments that spell out reasons why such an order can be considered preferable to alternative arrangements, and what can be done to establish and maintain it. ${ }^{1}$ By contrast, evolutionary agnosticism refers to a certain tenor in Hayek's thoughts on cultural evolution that seems to suggest that any efforts in deliberate institutional reform and construction must ultimately be futile in the face of an evolutionary process that pays no attention to what we may consider to be desirable or beneficial. ${ }^{2}$

Cato Journal, Vol. 14, No. 2 (Fall 1994). Copyright (O Cato Institute. All rights reserved. The author is Professor of Economics at the University of Freiburg. The article is based on a paper that was originally presented at the Mont Pelerin Society's General Meeting in Cannes, September 1994. Support of this research by the Earhart Foundation is gratefully acknowledged. I also wish to thank Georg Vanberg for helpful comments.

${ }^{1}$ This message is visible, for instance, when Hayek says about his The Constitution of Liberty that its "emphasis is on the positive task of improving our institutions" (1960: 5), and when he declares, "So far as possible, our aim should be to improve human institutions" (ibid.: 30). ${ }^{2} \mathrm{~A}$ particularly noteworthy expression of Hayek's evolutionary agnosticism can be found in The Fatal Conceit. In reference to his theory of cultural evolution Hayek notes, "I have no intention to commit what is often called the genetic or naturalistic fallacy. I do not 
That such a tension exists in Hayek's work is certainly not a new discovery. Others have noted it before, like Chandran Kukathas who concludes that Hayek's "thought is governed by two incompatible philosophical attitudes" (1990: 206), or Norman Barry who points to the inconsistency between, on the one hand, Hayek's "critical rationalism" and, on the other hand, "a certain kind of fatalism, that we must wait for evolution to pronounce its verdict" (1994: 160). My aim is not to repeat that Hayek's work suffers from the noted tension. Rather, my purpose is to show that this conflict can be reconciled in a manner that, while requiring a reinterpretation of some of Hayek's arguments, is truthful to the principal thrust of his overall approach.

The fact that Hayek's rational liberalism is mainly expressed in some of his earlier writings, while the evolutionary theme has become increasingly prominent in his later writings, has led some critics to conclude that the evolutionary argument represents the more mature version of Hayek's liberalism. Such an interpretation is, unfortunately, reinforced by the prominent role that The Fatal Conceit (1988) plays in the current debate on Hayek's thought. As his last major publication and as the first volume of his Collected Works, it has gained disproportional attention and is widely regarded as the definitive and authoritative summary of his ideas. Yet it is also the book in which Hayek's rational liberalism is least visible.

In a sense, this paper can be understood as an effort to prevent Hayek's legacy from being unduly overshadowed by the message of evolutionary agnosticism that seems to come out of The Fatal Conceit. Like some other of Hayek's later writings, this book adds an important dimension to his liberal paradigm. But, considered only by itself and apart from the rationalist dimension of Hayek's liberalism, it is bound to be misleading.

\section{Hayek on the Positive Tasks of Liberal Legislation}

Classical liberalism clearly had a reformist thrust, and with his efforts to provide a modern restatement of the philosophy of classical liberalism Hayek aimed, no less than the classical founders, at portraying the fundamental principles of a desirable social order, and at identifying provisions that are required to establish and maintain such an order. ${ }^{3}$ It has been said of Adam Smith and other 18th century

claim that the results of group selection of traditions are necessarily 'good'-any more than I claim that other things that have long survived in the course of evolution, such as cockroaches, have moral value" (1988: 27).

${ }^{3}$ As Kukathas notes, throughout his work Hayek's "primary concern has been to elucidate and defend the principles of a liberal social order" (Kukathas 1990: 166). 
founders of classical liberalism that they were largely engaged in what may be described as the "science of legislation," i.e. in a systematic effort to examine the working properties of the ground-rules of social order, and to identify possibilities for their improvement. ${ }^{4}$ Hayek clearly understood his own enterprise as a continuation of such a liberal science of legislation.

Distancing himself from the laissez-faire-image of liberalism Hayek sought to draw attention to the positive role that government has to play in providing and maintaining a framework of rules and institutions that allow a liberal order to flourish. As he noted (1948: 17) about the study of this issue,

Neither the much abused and much understood phrase of "laissez: faire" nor the still older formula of "the protection of life, liberty, and property" are of much help. In fact, in so far as both tend to suggest that we can just leave things as they are, they may be worse than no answer; they certainly do not tell us what are and what are not desirable or necessary fields of government activity.

In his 1939 article "Freedom and the Economic System" as vvell as in The Road to Serfdom, Hayek took particular care to point out that his criticism of modern planners was not about "whether we ought to choose intelligently between the various possible organizations of society" (Hayek 1976 [1944]: 35), but about the ways in which we can reasonably hope to improve the order of society by planning and rational construction. There is, he argues, an important distinction between two kinds of "social planning," namely the "distinction between the construction of a rational system of law, under the rule of which people are free to follow their preferences, and a system of specific orders and prohibition" (1939: 9). While liberalism denies that the latter kind of social planning can be a suitable tool for social improvement, it is not only compatible with the former type of planning, but, in Hayek's understanding, has to consider it the principal means by which we can hope to improve our social condition. ${ }^{5}$

The paper on "Free Enterprise and Competitive Order" that Hayek presented in 1947 at the initial meeting of what was later to become

\footnotetext{
${ }^{4}$ For a discussion of this issue see, for instance, Hayek (1969: 172; 1973: 4; 1978: 136), E. West (1990: 118), H. Albert (1979: 27).

${ }^{5}$ Hayek (1939: 8f.): "We can 'plan' a system of general rules, equally applicable to all people and intended to be permanent (even if subject to revision with the growth of knowledge), which provides an institutional framework within which the decisions as to what to do and how to earn a living are left to the individuals." Hayek, in fact, notes as a shortcoming of the liberal tradition that the "task of creating a rational framework of law has by no means been carried through consistently by the early liberals" (Hayek 1939: 11). He even suspects that the neglect "of this kind of planning ... has tended to throw the whole liberal doctrine into discredit" (ibid.).
} 
the Mont Pelerin Society (published in Hayek 1948: 107-18) stressed the role that the classical liberal doctrine, in his view, ought to assign to the positive task of improving the "legal framework." He suggests there that it is more adequate to interpret "the fundamental principle of liberalism" not as absence of state activity, but "as a policy which deliberately adopts competition, the market, and prices as its ordering principle and uses the legal framework enforced by the state in order to make competition as effective and beneficial as possible" (1948: 110).

In a handbook article on Liberalism, written in 1973, Hayek included a section entitled "Positive Tasks of Liberal Legislation" in which he refers approvingly to certain "neoliberal" approaches that explicitly address the issue of what the positive content of the legal framework must be in order "to make the market mechanism operate satisfactorily" (1978: 146). Though he did not specify which neoliberal approaches he had in mind, his description certainly fits German Ordo-liberals of the so-called Freiburg School, like Walter Eucken and Franz Boehm. ${ }^{6}$ It corresponds to their understanding of the role of liberal legislation when Hayek (1976 [1944]: 18) notes that the "attitude of the liberal toward society is like that of the gardener" who seeks to create favorable conditions for natural growth.

\section{Hayek's Evolutionism}

The theoretical context in which Hayek places his evolutionary argument is familiar, and a brief summary may suffice here. ${ }^{7}$ Speaking of the "twin ideas of spontaneous order and evolution" he emphasizes the close connection between his evolutionary argument and his concept of spontaneous order. A spontaneous social order results from the interplay of actors who pursue their respective interests within the confines of certain general rules of conduct. The nature of the resulting order will critically depend on the nature of the general rules that govern their behavior. In Hayek's terminology, the nature of the order of rules will determine the character of the resulting order of actions. Not any order of rules will result in an order of actions with desirable properties. For a beneficial order to emerge "suitable" or "appropriate" rules are required (Hayek 1969: 180). This raises the question of how we may hope to find such rules, and it is in this context that Hayek advances his theory of cultural evolution, i.e. the notion of a spontaneous evolutionary process in which alternative rules are experimented with and in which, through trial and error,

\footnotetext{
${ }^{6}$ For a brief characterization of the "Freiburg School," see Vanberg (1991).

${ }^{7}$ For a more detailed discussion, see Vanberg (1986, 1994a).
} 
experience about which kinds of rules work well and which do not is accumulated.

Hayek's theory of cultural evolution is not a tightly reasoned, well integrated body of arguments, but, instead, a more loosely connected set of general ideas and conjectures that have invited a number of criticisms.$^{8}$ In the present context my exclusive interest is in examining whether and, if so, in what regards his evolutionary theory has implications that would be inconsistent with what I have described above as his rational liberalism. When looked at more closely, it is quite apparent that by no means all of Hayek's arguments on the issue of cultural evolution are incompatible with his emphasis on the positive tasks of liberal legislation. No such incompatibility exists, for instance, for those parts of his evolutionary approach that are essentially concerned with the factual, historical origins of existing rules. The claim, for instance, that "most of the rules which do govern existing society are not the result of our deliberate making [but] ... the product of a process of evolution" (Hayek 1967: 92) may well be, and probably is, correct. The factual issue whether beneficial institutions did in factor can, in principle-come about without foresight, is different from the political issue whether, and to what extent, we should employ rational institutional analysis and deliberate reform in our efforts to improve our social condition. That good things came, and may come, about without foresight does surely not imply that we should proceed without foresight, whether in institutional or in other matters.

A conflict between Hayek's rational liberalism and his evolutionary thoughts can only exist if, and to the extent that, the latter implies the claim that we can trust the forces of cultural evolution to promote the emergence of desirable rules more effectively than efforts in deliberate constitutional design, or that it may even be detrimental to seek to interfere in the evolutionary process by rational constructive reform. In order for Hayek's evolutionary argument to actually have such implications it would have to make certain kinds of claims, claims of a factual and of a normative nature. Namely, on the one hand, the factual claim that cultural evolution will tend to select in favor of institutions with certain predictable properties, and, on the other hand, the normative claim that institutions with these kinds of characteristics are beneficial. More briefly, in order to have the noted implications, Hayek's evolutionary argument would have to have empirical and normative content. It would need to have empirical content in

\footnotetext{
${ }^{8}$ Ulrich Witt (1994: 184) concludes from his discussion of Hayek's evolutionary argument: "On a closer look it turns out that the theory of societal evolution appears rather unfinished and leaves several questions open."
} 
the sense that it tells us what kinds of rules and institutions can be expected to prevail in evolutionary competition. And it would need to have normative content in the sense that it would tell us why the kinds of rules and institutions that tend to survive in evolutionary competition are desirable ${ }^{9}$ We therefore need to examine the question what empirical and what normative content Hayek's theory can be said to actually possess.

\section{On the Empirical Content of Hayek's Evolutionism}

When Hayek says that evolutionary competition leads to "the survival of the successful" (1960: 57), "to the prevalence of the more effective institutions" (1979: 154), or to "successful adaptations of society" (1960: 34), such statements may seem to imply a substantive claim about the working properties of the evolutionary process. Yet, the notion of the survival of the successful is no more than a tautology. If it is to have explanatory content properties must be specified that are conceptually independent of survival, yet are claimed to be de facto attributes of successful institutions. The obvious problem is, of course, that such attributes cannot be identified as long as one leaves the particular nature of the evolutionary process unspecified. In other words, we need to know under what kinds of constraints the relevant process occurs before we can form any meaningful conjectures about the likely properties of successful contenders. For instance, knowing what the standard rules for tennis tournaments are, we can say which kinds of skills successful players are likely to have, and we can predict that players with such properties will tend to survive in tournaments. Such a prediction need, of course, not be perfect, because players' momentary disposition as well as random factors may affect the outcome in any particular tournament. Yet, the standard rules impose constraints on the competitive process that allow us to form expectations about the properties of successful players. By contrast, if we had no knowledge whatsoever about the rules of the tournament, we would scarcely be able to make any prediction about the properties that surviving players are likely to exhibit.

Elsewhere (Vanberg 1994a) I have suggested the distinction between conditional and unconditional evolutionary claims or conjec-

\footnotetext{
'If Hayek's evolutionary argument had no empirical content, i.e. if it did not say which kinds of rules evolution tends to favor, we could, for obvious reasons not conclude that those which survive are desirable. If, on the other hand, Hayek's theory did say something about the likely attributes of surviving institutions, but had no normative content, i.e. provide no argument why institutions with such attributes are desirable, we would have no reason to conclude that we ought to relinquish efforts in institutional design and, instead, leave our fate to the workings of evolutionary forces.
} 
tures to help to clarify what is at issue here. Unconditional claims are statements about evolution per se, statements that leave totally unspecified the kinds of constraints under which the evolutionary process occurs. Such claims provide no substantive information about what it is that can be expected to survive. Conditional claims, by contrast, are statements about the working properties of evolutionary processes under specified constraints. To the extent that the constraints under which evolutionary competition occurs are known, what is likely to make contenders successful can be defined independently of observed survival, turning the notion of the survival of the successful into an empirically contentful conjecture.

If the Hayekian argument that cultural evolution is a process "guided not by reason but by success" (Hayek 1979: 166) is to be more than a tautological exercise, it must be interpreted as a conditional conjecture. It must be an argument about what kinds of rules or institutions we can expect to survive if, and to the extent that, the evolutionary process is subject to certain specified constraints. Since Hayek nowhere explicitly discusses the kinds of constraints that his conjectures on the working properties of evolutionary competition presuppose, we need to some extent to reconstruct his argument. ${ }^{10}$ As I shall argue below, important clues as to what a spelled-out Hayekian conditional evolutionary argument should look like can be found in his treatment of market competition.

\section{On the Normative Content of Hayek's Evolutionism}

Yet, we need not only concern ourselves with the empirical content of Hayek's evolutionism, a discussion of its normative content is equally crucial. The question that needs to be examined here is, whether Hayek does, indeed, claim that what survives in cultural evolution is desirable and, if so, what his criterion of desirability is. ${ }^{11}$

Some of Hayek's comments on the evolutionary theme sound as if he has no intention at all to make any normative claim but, instead, aims only at a purely empirical explanatory argument. Such intention

\footnotetext{
${ }^{10}$ The notion of cultural evolution as a totally unconstrained process, as a process that includes all conceivable competitive strategies, may seem to be implied when Hayek (1988: 121) notes on the concept of group-selection: "Although the displacement of one group by another, and of one set of practices by another, has often been bloody, it does not need always to be so" (Hayek 1988: 121).

"In order for the claim that the results of cultural evolution are desirable to be meaningful, one need to be able, of course, to say something about the kinds of results the evolutionary process can be expected to produce. In other words, only on the basis of an evolutionary theory with empirical content can the issue of the desirability of evolutionary outcomes be meaningfully discussed.
} 
seems implied, for instance, in the already quoted (fn. 1) statement from The Fatal Conceit in which Hayek assures us: "I do not claim that the results of group selection of traditions are necessarily 'good'any more than I claim that other things that have long survived in the course of evolution, such as cockroaches, have moral value" (1988: 27). And any normative intention seems to be equally absent when, elsewhere in The Fatal Conceit, he argues that "demands for justice are simply inappropriate to a naturalistic evolutionary processinappropriate not just to what has happened in the past, but to what is going on at present ... Evolution cannot be just" (1988: 74).

If Hayek's discussion on cultural evolution were, indeed, meant as a purely naturalistic argument, the issue that this paper seeks to discuss would, of course, disappear. If no claim were made that cultural evolution tends to generate beneficial institutions, Hayek's argument would have no implications for the issue of rational institutional construction. In other words, a purely naturalistic theory of cultural evolution could be in conflict with Hayek's rational liberalism, except if it were to imply that efforts in "liberal legislation" are in vein because human design can do nothing against the dictates of evolution. Some of Hayek's comments in The Fatal Conceit may, indeed, seem to imply such an argument, for instance, when he notes that "we may not like the fact that our rules were shaped mainly by their suitability for increasing our numbers, but we have little choice in the matter now (if we ever did)" (1988: 134), and when he adds, "In any case, our desires and wishes are largely irrelevant" (ibid.).

If, by statements like these, Hayek merely wants to point to the fact that human values are not outside the evolutionary process but, instead, are themselves a product of evolution, ${ }^{12}$ he is certainly correct. But what does this argument imply? Does it, indeed, mean that our wishes and desires are largely irrelevant? Does it mean that our values should not serve as a standard for constructive reform? What other values should guide efforts in institutional design, or should there be no such efforts at all? If Hayek's evolutionary argument is meant to lead to recommendations concerning matters of institutional reform, how are we to evaluate such recommendations if not in terms of our own values? Upon closer examination Hayek's reasoning in this context seems to boil down to an argument about the superior wealth-creating potential of market institutions, and about the disastrous consequences

\footnotetext{
${ }^{12}$ Hayek (1978: 38): "But the basic conclusion that the whole of our civilization and all human values are the result of a long process of evolution in the course of which values continue to change, seems inescapable in the light of our present knowledge."
} 
that can be predicted to result from their destruction. ${ }^{13}$ This argument can, however, be readily defended on rational grounds, and Hayek himself has articulated these rational grounds more forcefully than anybody else.

Notwithstanding the naturalistic parts of Hayek's thoughts on cultural evolution, the general thrust of his work on the subject clearly suggest that his evolutionary argument is meant to be of significance for the normative issue of how we should deal with the rules and institutions within which we operate. The question, therefore, is what is the normative criterion that he employs?

Though Hayek cannot be said to be totally unambiguous in this matter, the principal candidate, I submit, is a criterion that not only appears again and again throughout his work, but that is also most consistent with the classical liberal foundations of his philosophy, namely the notion that institutions are beneficial if, and to the extent that, they benefit the persons living with them. ${ }^{14}$ In other words, I claim that it is the desirability for their individual constituents, that make rules and institutions beneficial in Hayek's account. This criterion clearly seems implied when Hayek (1960: 5) notes about the "positive task of improving our institutions" that, in order to "produce desirable and workable results," such efforts need to be "guided by some general conception of the social order desired, some coherent image of the kind of world in which people want to live" (ibid.: 114).$^{15}$ If one wants to use a label, one can characterize this standard as normative individualism (Buchanan 1991).

The classical liberalism of David Hume and Adam Smith embodied, as Hayek notes, a "conception of a desirable order" (Hayek 1967: 160). Hayek's own restatement of their liberal principles shares their

\footnotetext{
${ }^{13}$ As Hayek (1988: 134) notes:

So many people already exist; and only a market economy can keep the bulk of them alive.... Since we can preserve and secure even our present numbers only by adhering to the same general kinds of principles, it is our duty-unless we truly wish to condemn millions to starvation - to resist the claims of creeds that tend to destroy the basic principles of these morals, such as the institution of several property. In any case, our desires and wishes are largely irrelevant. Whether we desire further increases of production and population or not, we must-merely to maintain existing numbers and wealth, and to protect them as best we can against calamitystrive after what, under favorable conditions, will continue to lead, at least for some time, and in many places, to further increases.

${ }^{14}$ Note that "better off" can be interpreted in a subjective as well as in an objective sense. In its subjective interpretation necessarily the interests of the persons involved are the relevant measuring rod. In its objective interpretation, by contrast, some objective measure of wealth would be the standard. It is not always unambiguously clear which version Hayek wants to apply. It seems to me that only the subjective interpretation is consistent with his overall philosophy.
} 
concern, as well as their individualist understanding of what constitutes a desirable social order. This is apparent, for instance, when he describes the latter as "the kind of world in which people want to live" (1960: 114), or when he speaks of the "endeavor to make society good in the sense that we shall like to live in it" (1973: 33). ${ }^{15}$ The same criterion of desirability is implied when he defines the "conception of the common welfare or the common good of a free society" as an abstract order which provides "the best chance for any member selected at random successfully to use his knowledge for his purposes" (1967: 163). And it is quite explicitly stated when Hayek suggests that "we should regard as the most desirable order of society one which we would choose if we knew that our initial position in it would be decided purely by chance (such as the fact of our being born into a particular family)" (1976: 132).

\section{Markets: Competition Within Constraints}

What does the criterion of the desirability of rules and institutions, namely their desirability to their constituents, imply for Hayek's evolutionary argument? To argue that the evolutionary process selects in favor of beneficial or desirable institutions would mean to claim that cultural evolution favors institutions that are desirable to the persons involved. Note that the normative component lies only in the notion that the relevant criterion for the desirability of institutions is the desirability to their constituents. The claim that cultural evolution selects in favor of rules and institutions that are desirable in this sense is, as such, not a normative but a factual claim, namely the conjecture that the evolutionary process is such that it will favor institutions with attributes that their constituents find desirable. This conjecture can, quite obviously, be correct or false. In the generality in which it is stated, it seems to be false; and we can certainly suppose that Hayek would not have agreed that this is what he meant. But, if he does not mean to say that evolutionary competition universally produces desirable results in the above sense, what claim can be inferred from his argument?

The answer to this question lies, in my view, in the distinction that I introduced earlier between conditional and unconditional evolutionary claims. How this distinction can help to clarify Hayek's evolutionary

\footnotetext{
${ }^{15}$ Hayek (1978: 37):

Since Adam Smith ... a market economy has . . been likened to a game in which the results for each depend partly on his skill and effort and partly on chance. The individuals have reason to agree to play this game because it makes the pool from which the individual shares are drawn larger than it can be made by any other method.
} 
argument can be clearly seen if we look at his theory of the market process from this perspective. I shall, therefore, apply the distinction first to his view of the market, before returning to his evolutionary theory.

According to Hayek, the fundamental principle of liberalism lies in "a policy which deliberately adopts competition, the market, and prices as its ordering principles" (1948: 110). Apart from what he has to say on the socialist calculation issue, Hayek's main argument in favor of market competition is its role as a discovery process. Markets, he reasons, not only allow for the utilization of knowledge fragmented and dispersed among innumerous individuals. They also promote the growth of problem-solving-knowledge by providing an arena for trying out and competitively comparing tentative alternative solutions for a wide range of problems. Since we cannot know in advance what goods and services consumers will value most, nor how these goods and services can be produced most efficiently, we have good reasons, Hayek argues, to rely on markets as arenas in which the independent and competitive efforts of many result in a process of constant exploration and learning. Or, more generally, since we can never know in advance what the best solutions to our problems may be, we should make sure that the possibility as well as the incentives exist to try out new ways of doing things that may prove to be superior to existing practices. ${ }^{16}$

When Hayek suggests that the described features of market arrangements are desirable, he clearly means that they are desirable to the persons involved, in the sense that they "secure for any random member ... a better chance over a wide range of opportunities available to all than any rival system could offer" (1988: 85). Yet, this claim is not an unconditional claim. It is not made for competition per se, irrespective of its terms, and not for any kind of spontaneous process, no matter what its particular nature. No less than those before him in the classical liberal tradition, Hayek is quite explicit about the fact that, in order to have the noted desirable properties, market competition has to be constrained by appropriate rules of the game, by a legal framework that guides the competitive efforts of market participants into socially productive directions.

In fact, what liberals like Hayek mean by the very term market competition is constitutionally constrained competition, competition within rules that assure its beneficial working. As he points out, it has been commonly taken for granted in the liberal tradition that "a

${ }^{16}$ For a more detailed discussion of this theme, see Vanberg (1993) and Vanberg and Kerber (1994). 
functioning market presupposes not only the prevention of violence and fraud but the protection of certain rights, such as property, and the enforcement of contracts" (1948: 110f.). Moreover, he sees this whole issue as a continuing challenge, as a problem that we cannot hope to solve once and for all, but that requires us to constantly monitor the ways in which the existing order of rules affects the properties of the resulting order of actions under constantly changing circumstances, and in the light of our constantly changing knowledge. As noted earlier, if he has any quarrels with his liberal predecessors, it is because, in his view, they did not always pay sufficient attention to the issues that arise beyond an acceptance of the general principles of private property and freedom of contract, namely, to determine what, under given circumstances, the most appropriate form of the rules of property and contract may be. ${ }^{17}$

When Hayek advocates competitive markets as desirable social arrangements, it is quite obvious that he intends to make, in terms of the above distinction, a conditional rather than an unconditional claim about the workings of the competitive process: the beneficial working of the market process is seen contingent on the nature of the constraining framework of rules. And to the extent to which we can determine the conditions or rule-constraints that are favorable to the beneficial working of market competition, we may seek to create or establish such conditions. ${ }^{18}$ In this sense the concept of the market process as a spontaneous, evolutionary process and the notion of deliberate institutional design are not only compatible with each other; they are necessarily linked with each other. The liberal understanding of institutional requirements for a well-working market implies that there is a role for what the German Ordo-liberals called Ordunungspolitik, a policy specifically aimed at providing and maintaining a

\footnotetext{
${ }^{17}$ Hayek (1976 [1944]: 38):

It is by no means sufficient that the law should recognize the principle of private property and freedom of contract; much depends on the precise definition of the right of property as applied to different things. The systematic study of the forms of legal institutions which will make the competitive system work efficiently has been sadly neglected.

The general criterion that Hayek sees for "an appropriate legal system" is expressed in his statement:

The main condition on which the usefulness of the system of competition and private property depends: namely, that the owner benefits from all the useful services rendered by his property and suffers all the damages caused to others by it [ibid.].

${ }^{18}$ Hayek (1978: 184): "Therefore it clearly makes sense to try to produce conditions under which the chances for any individual taken at random to achieve his ends as effectively as possible will, be very high." See also Hayek (1967: 173): "An optimal policy in a catallaxy may aim, and ought to aim, at increasing the chances of any member of society taken at random."
} 
suitable legal framework for the market order. If, and to the extent that, an appropriate framework of rules cannot be expected to spring up naturally, and to be maintained as well as continuously adjusted by spontaneous forces alone, deliberate efforts in institutional design and legislative reform are essential ingredients to a viable liberal order.

The Ordo-liberals distinguished clearly between the spontaneous internal workings of the market and the question of how the institutional framework that conditions the market's operation is created and maintained. One of their central claims was that the market will not out of itself generate and maintain a framework of rules that assures its beneficial working. The task of providing such a framework was, in their view, unavoidably a political task. Though Hayek's evolutionary argument occasionally sounds as if he believes in the spontaneous, endogenous generation of the rules within which markets operate, such sporadic evidence is far outweighed by numerous arguments, such as those documented above, which clearly state the important role that he assigns to deliberate institutional reform, to "a policy which ... uses the legal framework enforced by the state in order to make competition as effective and beneficial as possible" (Hayek 1948: 110). ${ }^{19}$

Understood as a conditional argument Hayek's evolutionary account thus tells us that we need, on one side, to rely on competitive evolutionary processes as discovery procedures, because we cannot know in advance what the best solutions to our problems may be, and that, on the other hand, we need to constrain evolutionary competition by a framework of appropriate rules in order to make it responsive to the interests of the persons involved. To the extent that the creation of such a framework requires deliberate legislative action, institutional design is not opposed to the role of spontaneous forces, but is a prerequisite for their beneficial working.

There is a second sense in which the market-example shows that design and evolutionary competition are compatible and complementary notions. This aspect is quite obvious (and, therefore, rarely discussed explicitly) in the case of market processes, but it is far less obvious and more significant in the case of cultural evolution. A brief look at the market-version of the argument can help to recognize clearer its relevance for the discussion on cultural evolution.

As noted earlier, from a Hayekian evolutionary perspective the market can be viewed as an arena in which alternative solutions to a

\footnotetext{
${ }^{19}$ Hayek speaks of "the task of gradually amending our legal system to make it more conducive to the smooth working of competition" (1960: 230).
} 
wide range of problems compete within the confines of certain rules of the game. The spontaneous nature of the competitive market process is dependent on the nature of these rules. But it is not necessary that these rules are themselves of spontaneous origin. They may well be deliberately designed. This concerns the first sense in which design can be compatible with spontaneous evolution. The second sense in which such compatibility exists, concerns the simple fact that the inputs into the competitive market process may well be designed without invalidating in the least the spontaneous, evolutionary nature of the overall process. The problem-solutions that are entered into the competition typically are, to a larger or lesser extent, the product of explicit rational planning. Cars and video-recorders are, of course, designed products. And the same is, to a large extent, true for the solutions to social-institutional problems that compete in markets, such as the organizational structure of business firms.

What is essential for an evolutionary process is not that its competing inputs are undesigned, or that its constraining rules are of spontaneous origin. What is essential is that the framing rules are of a kind that allows for, and maintains, a competitive process with desirable characteristics, desirable, that is, for the persons involved. A principal feature of a well-functioning competitive order is, in Hayek's account, its openness to the entry of alternative, and potentially superior, problemsolutions. Such a competitive order, he argues, "does not presuppose what economic theory calls 'perfect competition' but only that there are no obstacles to the entry into each trade and that the market functions adequately in spreading information about opportunities" (Hayek 1967: 174).

\section{Cultural Evolution and Designed Experiments}

My principal conjecture in this paper is that Hayek's theory of cultural evolution, in order to be a meaningful and consistent part of his liberal philosophy, must be interpreted in light of his argument on market competition. That is, it must be read not as an unconditional argument about institutional competition per se, in whatever terms it might occur, but as a conditional claim about the workings of evolutionary competition within certain constraints. If interpreted in this fashion, Hayek's argument on cultural evolution is just as compatible with the notion of deliberate design as is his argument on market competition. It allows for the institutional inputs into the evolutionary process to be designed. And it requires deliberate efforts in creating and maintaining a framework of rules that serves to make the evolutionary process work in favor of institutions that are desirable to their 
constituents. The first issue will be discussed in the present section, the second in the last section of this paper. ${ }^{20}$

Deliberate institutional reforms are an essential part of the experimental input into the evolutionary process. Though part of this input may indeed, as Hayek (1960: 32) suggests, consist of "undesigned novelties that constantly emerge in the process of adaptation," designed novelties surely play an important part as well. There is no contradiction between the notion of deliberate institutional design and the notion of a competitive evolutionary process, just as there is no contradiction between the notion of deliberate organized production and the notion of a spontaneous market process in which such deliberate production experiments compete. The evolutionary nature of the overall process is solely related to the fact that the experimental inputs are subject to competitive selection in an environment that is open for the entry of new challengers.

Similarly, Hayek's view on cultural evolution is based on the argument that in the realm of rules as well we ought to rely on competition as a discovery procedure (Hayek 1978: 149; 1979: 67ff.). His argument against constructivist rationalism in the realm of rules and institutions is not meant as an objection against institutional design per se but against excessive claims that ignore the limits of our knowledge and reason. His critique aims at the "pretense of knowledge" that underlies proposals for a total redesign of our social order ${ }^{21}$ and the exclusive privileges and monopolistic power associated with such efforts. Or, stated positively, Hayek argues for piecemeal and corrigible reforms that are carried out in awareness of the fallibility of our efforts. He favors competitive arrangements where alternative conjectural solutions can be compared, and established practices can be challenged by new institutional conjectures, whether these are deliberately designed or emerge unintendedly.

\footnotetext{
${ }^{20}$ In the course of this discussion I hope to clarify the issue that Kukathas (1990: 103f.) raises: Hayek is not an anarchist. He sees a place for politics in the development of the institutions of justice, he does not present what might be termed a 'pure theory of spontaneous order'. Indeed, the market can only flourish, in his view, if sound institutions of justice, law, and property are put in place. Yet it is obscure how far these institutions arise 'spontaneously', when it is permissible to alter them, or what criteria we may use to evaluate their functioning.... While Hayek has developed a theory of the spontaneous order forces of society, he has not come up with an explanation of the extent to which reason can criticize and try to alter the direction of social development.

I seek to show that what Kukathas sees lacking can be reconstructed from Hayek's own argument.

${ }^{21}$ Hayek (1960: 63): "Although we must always strive to improve our institutions, we can never aim to remake them as a whole."
} 
Hayek's argument in favor of utilizing the explorative potential of competitive evolutionary settings cannot sensibly be employed against the use of rational analysis and of reason in matters of institutional reform, as he explicitly states (Hayek 1960: 70):

None of these conclusions are arguments against the use of reason, but only arguments against such uses as require any exclusive and coercive powers of government; not arguments against experimentation, but arguments against all exclusive, monopolistic power to experiment in a particular field-power which brooks no alternative and which lays a claim to the possession of superior wisdom-and against the consequent preclusion of solutions better than the ones to which those in power have committed themselves. ${ }^{22}$

In contrast to the constructivist rationalism he rejects, Hayek suggests for his own approach the term "evolutionary rationalism" (1973:5). With this label he wants to describe an attitude that combines the notion of rational institutional reform with the willingness to have one's designs exposed to an environment in which they can be challenged by alternative, and potentially superior constructions. He does not advocate "an abdication of reason" (Hayek 1960: 69) but an awareness of its conjectural nature, and its use within a framework in which it is subject to the discipline of an experimental and competitive process. The contrast that he has in mind is "between conditions, on the one hand, in which alternative ways based on different views or practices may be tried and conditions, on the other, in which one agency has the exclusive right and the power to prevent others from trying" (Hayek 1960: 37).

To advocate the utilization of competitive evolutionary processes as a critical check on our institutional constructions is not the same as to claim that we could get along without any rational institutional design. Such a claim would be analogous to advocating a competitive automobile market and saying that this market could function without the design-work of engineers and production-planers. Furthermore, the argument for the utilization of evolutionary competition is itself a rational argument. It means that a proper insight into the limits of our knowledge and reason should lead us, on rational grounds, to stay away from exclusive, monopolistic solutions, and to opt, instead, in favor of competitive frameworks. We should use our reason and knowl-

${ }^{22}$ See also Hayek (1988: 8):

By "reason properly used" I mean reason that recognizes its own limitations.... How, after all, could I be attacking reason in a book arguing that socialism is factually and even logically untenable? Nor do I dispute that reason may, although with caution and humility, and in a piecemeal way, be directed to the examination, criticism and rejection of traditional institutions and moral principles. ... Thus I wish neither to deny reason the power to improve norms and institutions. 
edge to improve the order of rules under which we live. But we should take into account and prepare for the fact that our designs are fallible, that they may turn out to be failures, or inferior to potential alternatives. In this sense liberalism is based on an "intellectual humility which ... regards with reverence those spontaneous social forces through which the individual creates things greater than he knows" (Hayek 1992: 244). The principal conclusion that Hayek suggests to us is that in no area of human problem-solving efforts, neither in those that we entrust to ordinary markets, nor in those which we seek to solve through the political process, can we know in advance what the best solution may be, and that, therefore, we ought to rely on competitive, explorative processes wherever possible.

\section{Evolution Within Constraints: The Role of Ordnungspolitik}

A sensible interpretation of Hayek's theory of cultural evolution must view it as a conditional claim about evolutionary competition. If read as an unconditional claim about cultural evolution per se, Hayek's evolutionary argument makes little sense, and it would be inconsistent with the liberal thrust of his work. Yet, though it needs clearly to be understood as a conditional claim, Hayek has made very little effort to explicitly state what the relevant characteristics of a beneficial process of cultural evolution are, i.e. of a process that selects in favor of rules which are desirable to the persons in the relevant constituency. This means that we have to reconstruct his notion of a properly constrained process from his writings. And, as noted above, we can gain important suggestions on this issue from his thoughts on market processes. Just as his argument on market competition is a conditional one, namely, that competition works beneficially provided it is constrained by appropriate rules, his argument on cultural evolution as a process of competitive selection among rules and institutions needs to be qualified in similar ways.

All the arguments that have been made above about Hayek's conception of a beneficially working market process can be extended to his notion of cultural evolution, if both theories are to be considered as parts of a coherent liberal philosophy. This includes, in particular, what has been said about the role of liberal legislation or Ordnungspolitik. It is this kind of institutional politics that Hayek has in mind when he speaks of "liberal constitutionalism" (1969: 199), and when he talks of the task to provide "a beneficial framework for the free growth of society" (1979: 152), the task to "create the conditions in which society can gradually evolve improved formations" (ibid.: 14). 


\section{Cato Journal}

Hayek has been quite explicit about the role of liberal legislation or Ordnungspolitik with regard to the market process. Yet, just as he has not been very explicit about the relevant constraints for a beneficially working process of cultural evolution, he has been conspicuously silent about the role that Ordnungspolitik would have at this level. A principal reason for this seems to me to lie in Hayek's failure to take into account the difference between two kinds of "design-approaches," a difference that he clearly thought relevant in his discussion of market processes. There he emphasizes the distinction between Ordnungspolitik (without using this term, though) and interventionism, that is, between a policy that aims at the general framework of rules within which market processes unfold, and a policy that seeks to bring about particular outcomes by intervening in the market process by specific measures. While Hayek objects to the second type of policy on the grounds that it runs counter to the very working properties of markets, he expressly states that the first is not only compatible with market principles but is the main instrument by which we can seek to make markets work better. ${ }^{23}$

Logic requires that the same distinction between types of policies be made with regard to the process of institutional competition that Hayek's theory of cultural evolution is concerned with. Here, too, we need to distinguish between a policy that seeks to constrain the process of cultural evolution by a framework of rules, and a policy that intervenes into the evolutionary process with specific measures in order to secure particular, predetermined outcomes. The first type of policy, a Ordnungspolitik for cultural evolution, is both compatible with an evolutionary process and a principal instrument for conditioning its general working properties. The second, by contrast, clearly falls under the same verdict that Hayek pronounces on interventionist policies in ordinary markets. Just as we cannot, at the same time, enjoy the benefits of the explorative potential of market processes and assure specific, predetermined results, we cannot benefit from the discovery procedure of cultural evolution and, at the same time, seek to direct the evolutionary process towards particular, predetermined outcomes.

\footnotetext{
${ }^{23}$ Hayek (1973: 51):

We can preserve an order of such complexity not by the method of directing the members, but only indirectly by enforcing and improving the rules conducive to the formation of a spontaneous order. ... This is the gist of the argument against "interference" or 'intervention' in the market order. ... What the general argument against 'interference' thus amounts to is that, although we can endeavor to improve a spontaneous order by revising the general rules on which it rests, ... we cannot improve the results by specific commands that deprive its members of the possibility of using their knowledge for their purposes.
} 
That at the level of cultural evolution just as at the level of ordinary market processes we need to distinguish between legitimate Ordnungspolitik and objectionable interventionism, is an insight that can clearly be reconstructed from Hayek's argument, but that he has not explicitly recognized. To the contrary, his comments on the issue sound as if he considers any effort to guide the process to fall under the verdict of interventionism. Referring to what he describes as the "morally blind results" of cultural evolution he argues, for instance, "Understandable aversion to such morally blind results, results inseparable from any process of trial-and-error, leads men to want to achieve a contradiction in terms: namely, to wrest control of evolution-i.e., of the procedure of trial-and-error-and to shape it to their present wishes" (Hayek 1988: 74). Such comments seem to ignore the critical difference between seeking to condition the general nature of a trialand-error process by means of a framework of rules of the game, and seeking to direct such a process towards predetermined outcomes. To seek to wrest control of evolution is, indeed, clearly incompatible with the open-ended nature of an evolutionary process, and on such efforts Hayek may rightly comment that "evolution cannot be guided by and often will not produce what men demand" (ibid.). But this does not mean that we cannot seek to guide evolution in the sense of constraining it by rules that serve to shape its general nature in a desirable fashion, much in the same sense that we seek to improve the general working properties of ordinary markets by suitable reforms of its institutional framework.

We have to note, however, that to use criteria for judging what kinds of institutions are desirable, and to determine the characteristics of evolutionary processes that are likely to select in favor of such institutions, is totally different from claiming to be able to determine in advance which particular results the process will generate. As I have sought to show above, Hayek's work clearly implies a criterion for evaluating institutions, namely the individualist standard that institutions should be considered desirable if, and to the extent that, they are judged so by their individual constituents. Analogous to the argument on the institutional prerequisites for beneficially working markets, for the process of cultural evolution as well we need to determine, and then to establish, those rule-constraints that promise to guide the evolutionary process in accord with a normative individualist standard (Vanberg 1994; Vanberg and Kerber 1994).

\section{Conclusion}

Once the (necessarily) conditional nature of Hayek's arguments on market competition and on cultural evolution is fully appreciated, the 
systematic connection between his evolutionary emphasis and his emphasis on the positive tasks of liberal legislation can be understood. We need to rely on evolutionary competitive processes as discovery procedures, because we cannot know in advance what the best solutions to our problems may be (nor can we know in advance, what new problems we may face tomorrow). On the other side, in order to make evolutionary competitive processes operate responsively to the interests of the individuals involved, we need to impose appropriate rule-constraints. And since we cannot know in advance what the most appropriate constraints may be, we need to rely, on the level of rules as well, on competition as a discovery procedure.

This integrated concept of cultural evolution and liberal legislation suggests a liberal perspective that appreciates Hayek's evolutionary argument without adopting the agnostic attitude that is characteristic of some of the contemporary reception of Hayekian evolutionism. It suggests a liberal perspective that emphasizes the positive task of liberal legislation in providing an appropriate institutional framework for market competition and cultural evolution, without taking on the rationalist arrogance that is the target of Hayek's critique of rational constructivism. It suggests a liberal perspective that sees a role for deliberate legislation in constraining evolution, and a role for evolutionary competition in constraining our efforts in deliberate institutional design.

\section{References}

Albert, H. (1979) "The Economic Tradition. Economics as a Research Programme for Theoretical Social Science." In Brunner, K. (ed.) Economics and Social Institutions, 1-27. Boston: Martinus Nijhoff.

Barry, N. P. (1994) "The Road to Freedom-Hayek's Social and Economic Philosophy." In Birner, J., and Zijp, R. van (eds.) Hayek, Co-Ordination and Evolution. His Legacy in Philosophy, Politics, Economics and the History of Ideas, 141-63. London: Routledge.

Böhm, F. (1980) "Freiheit and Ordnung in der Marktwirtschaft." In Mestmäcker, E.-J. (ed.) Freiheit und Ordnung in der Marktwirtschaft, 195-209. Nomos: Baden-Baden.

Buchanan, J. M. (1977) Freedom in Constitutional Contract-Perspectives of a Political Economist. College Station: Texas A\&M University Press.

Gray, J. N. (1982) "F. A. Hayek and the Rebirth of Classical Liberalism." Literature of Liberty 4: 19-66.

Hayek, F. A. (1939) Freedom and the Economic System. In Gideonse, H. D. (ed.) Public Policy Pamphlet, No. 29. Chicago: University of Chicago Press.

Hayek, F. A. (1948) Individualism and Economic Order. University of Chicago Press.

Hayek, F. A. (1956/57) “Über den 'Sinn' sozialer Institutionen.” Schweizer Monatshefte 36: 512-24. 


\section{YES! I want \\ to subscribe to the CATO JOURNAL.}

$\square 1$ year $\square 2$ years $\square 3$ years $(\$ 24.00) \quad(\$ 48.00)$

$(\$ 72.00)$

$\square$ New subscription

$\square$ Renewal

My name

Address

City

State Zip

(For foreign subscriptions, please add $\$ 5.00$ per year regular delivery and $\$ 10.00$ per year airmail delivery.)

My comments on the JOURNAL:

\section{Please enter a GIFT SUBSCRIPTION for the person(s) named below.}

$\square 1$ year $\square 2$ years $\square 3$ years $(\$ 24.00) \quad(\$ 48.00)$ $(\$ 72.00)$ $\square$ New subscription $\square$ Renewal Gift to

Address City

State Zip

$\square 1$ year $(\$ 24.00)$

2 years $(\$ 48.00)$

$\square$ New subscription

3 years

Gift to

Address

City

State Zip
Please start a subscription for the LIBRARY named below.

\section{$\square 1$ year $\square 2$ years $\square 3$ years} $(\$ 50.00) \quad(\$ 100.00) \quad(\$ 150.00)$ $\square$ New subscription $\square$ Renewal Library

Address

City

State Zip

Total: \$ $\square$ Check enclosed. Please bill my: $\square$ Visa $\square$ Mastercard Account \# Exp. date Signature

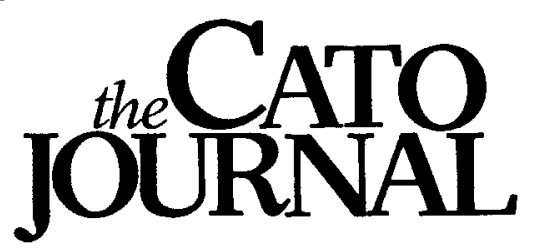




\section{BUSINESS REPLY MAIL}

FIRST CLASS PERMIT NO. 13690 WASHINGTON, D. C. 20024

Postage will be paid by addressee

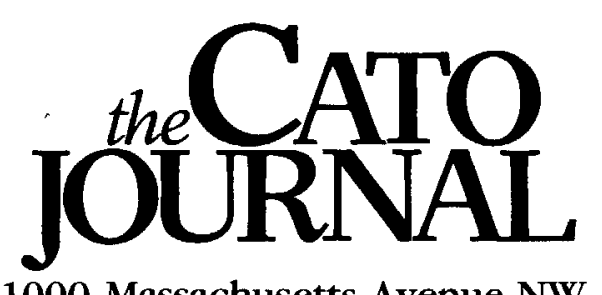

1000 Massachusetts Avenue NW

Washington, DC 20001 
Hayek, F. A. (1959) "Liberalismus (1)-Politischer Liberalismus." In Handwörterbuch der Sozialwissenschaften, Vol. 6, 591-96. Stuttgart: Gustav Verlag.

Hayek, F. A. (1960) The Constitution of Liberty. Chicago: University of Chicago Press.

Hayek, F. A. (1967) Studies in Philosophy, Politics and Economics. Chicago: University of Chicago Press.

Hayek, F. A. (1969) Freiburger Studien. Gesammelte Aufsätze. Tübingen: J. C. B. Mohr (Paul Siebeck).

Hayek, F. A. (1973) Law, Legislation and Liberty, Vol. 1. London: Routledge and Kegan Paul.

Hayek, F. A. (1976) Law, Legislation and Liberty, Vol. 2. London: Routledge and Kegan Paul.

Hayek, F. A. (1976 [1944]) The Road to Serfdom. Chicago: University of Chicago Press.

Hayek, F. A. (1978) New Studies in Philosophy, Politics, Economics and the History of Ideas. Chicago: The University of Chicago Press.

Hayek, F. A. (1979) Law, Legislation and Liberty, Vol. 3. London: Routledge and Kegan Paul.

Hayek, F. A. (1979a) Wissenschaft und Sozialismus. Walter Eucken Institut, Vorträge und Aufsätze 71. Tübingen: J. C. B. Mohr (Paul Siebeck).

Hayek, F. A. (1988) The Fatal Conceit. The Collected Works of Friedrich August Hayek, Vol. I. Chicago: University of Chicago Press.

Hayek, F. A. (1991) The Trend of Economic Thinking-Essays on Political Economy and Economic History. The Collected Works of Friedrich August Hayek, Vol. III. Chicago: University of Chicago Press.

Hayek, F. A. (1992) "Opening Address to a Conference at Mont Pelerin." In The Fortunes of Liberalism-Essays on Austrian Economics and the Ideal of Freedom, 237-48. The Collected Works of Friedrich August Hayek, Vol. IV. Chicago: University of Chicago Press.

Kukathas, C. (1990) Hayek and Modern Liberalism. Oxford: Clarendon Press.

Vanberg, V. (1986) "Spontaneous Market Order and Social Rules." Economics and Philosophy 2: 75-100.

Vanberg, V. (1992) Review of ORDO, Vols. 40 and 41. Constitutional Political Economy 2: 397-402.

Vanberg, V. (1993) "Constitutionally Constrained and Safeguarded Competition in Markets and Politics, with Reference to a European Constitution." Journal des Économistes et des Études Humaines 4: 3-27.

Vanberg, V. (1994a) "Cultural Evolution, Collective Learning, and Constitutional Design." In Reisman, D. (ed.) Economic Thought and Political Theory Boston, 171-204. Boston: Kluwer Academic Publishers.

Vanberg, V. (1994b) Rules and Choice in Economics. London: Routledge.

Vanberg, V., and Kerber, W. (1994) "Institutional Competition Among Jurisdictions: An Evolutionary Approach." Constitutional Political Economy 5: 193-219.

West, E. G. (1990) Adam Smith and Modern Economics. Aldershot: Edgar Elgar.

Witt, U. (1994) 'The Theory of Societal Evolution-Hayek's Unfinished Legacy." In Birner, J., and Zijp, R, van (eds.) Hayek, Co-Ordination and Evolution, 178-89. London: Routledge. 